\title{
INEFICACIA DEL DESPIDO INCAUSADO: PRIMACÍA NORMATIVA Y LA VULNERABILIDAD DE LA TRABAJADORA EMBARAZADA
}

\section{INEFFECTIVENESS OF THE INCAUSED DISMISSAL: NORMATIVE PRIMACY AND THE VULNERABILITY OF THE PREGNANT WORKER}

\section{Marcos Maximiliano Cáceres Falkiewicz'}

DOI: https://doi.org/10.37767/2591-3476(2021)17

\section{Comentario a}

Z., M. E. c/ C. S.A. - MEDIDA AUTOSATISFACTIVA

Juzgado de Conciliación y Trabajo de Cuarta Nominación - Secretaria Octava Poder Judicial de Córdoba

\section{Disponible en}

https://bit.ly/3BkqLVM

\section{RESUMEN:}

El Juzgado de Conciliación y Trabajo de Cuarta Nominación Secretaría Octava de la Provincia de Córdoba, resolvió hacer lugar a la demanda autosatisfactiva incoada por la trabajadora y en consecuencia, declarar la nulidad del despido dispuesto por la empleadora estando vigente tanto, el período de prueba del artículo 92 bis de la Ley de Contrato de Trabajo como así también, la prohibición de despedir consagrada por el Decreto de Necesidad y Urgencia Nro. 329/2020 dictado por el Poder Ejecutivo Nacional. Es decir, le otorgó primacía normativa a este DNU por sobre el artículo 92 bis de la LCT, atento la situación de vulnerabilidad de la trabajadora embarazada y en virtud de la excepcionalidad de la situación y jerarquía del bien jurídico tutelado constitucionalmente. 


\begin{abstract}
The Fourth Nomination Labor and Conciliation Court Eighth Secretariat of the Province of Córdoba, allowed the so called self-satisfying lawsuit filed by the worker and consequently, declare the nullity of the dismissal ordered by the employer during the trial period of article 92 bis of the Labor Contract Law and also with the current prohibition to dismiss guaranteed by the Decree of Necessity and Urgency No. 329/2020 issued by the National Executive Power. In other words, the court ruled the legal supremacy of the Decree of Necessity and Urgency over the article 92 bis, due to the vulnerable situation of the pregnant worker, the exceptionality of the situation and hierarchy of the constitutionally protected legally protected interest.
\end{abstract}

PALABRAS CLAVE: Trabajadora; embarazada; vulnerabilidad; primacía; constitucional.

KEY WORDS: Worker; pregnant; vulnerability; legal primacy; constitutional.

\title{
I. Introducción
}

El 26 de junio del año 2020, el Juzgado de Conciliación y Trabajo de Cuarta Nominación Secretaría Octava de la Provincia de Córdoba, resolvió hacer lugar a la demanda autosatisfactiva incoada por la trabajadora y en consecuencia, declarar la nulidad del despido dispuesto por la empleadora estando vigente tanto, el período de prueba del artículo 92 bis de la Ley de Contrato de Trabajo (en adelante, LCT) como así también, la prohibición de despedir consagrada por el Decreto de Necesidad y Urgencia Nro. 329/2020 (en adelante DNU) dictado por el Poder Ejecutivo Nacional. En este marco, la demandada debió reincorporar a la actora a su puesto de trabajo en las mismas condiciones en la que se encontraba antes del despido y abonar los salarios caídos correspondientes.

En virtud de la excepcionalidad de la situación y la jerarquía del bien jurídico tutelado constitucionalmente, el magistrado concluyó que existen elementos probatorios suficientes que demuestran que el despido debe enmarcarse dentro de la prohibición establecida por el DNU no 329/2020, es decir, que conforme los fundamentos que desarrollaremos infra, le otorgó primacía normativa a este DNU por sobre el artículo 92 bis de la LCT.

Asimismo, atento que la medida autosatisfactiva se despacha sin intervención de la contraria y que sobre esta cuestión no resulta pacifica ni la doctrina ni la jurisprudencia, el juzgador impuso las costas por su orden (art. 28 Ley 7987), ya que la demandada pudo entender que le asistía razón en su manera de obrar.

\section{Medidas Autosatisfactivas}

En el fallo que nos ocupa, podemos advertir que la trabajadora pretende resguardar y hacer valer sus derechos y garantías constitucionales a través de un instituto que forma parte de los denominados procesos urgentes: las medidas autosatisfactivas.

A tales medidas, autorizada doctrina las ha definido como una providencia dictada en el marco de un proceso autónomo, a los fines de satisfacer en forma definitiva una pretensión de urgente necesidad. Por ello, en palabras de Marcellino (2013) citada por el juzgador del caso, se requiere un interés tutelable manifiesto y la necesidad de que exista una tutela inmediata imprescindible. También, “... las medidas autosatisfactivas se erigen en 
instrumentos que permiten a los jueces dar una solución rápida a situaciones conflictivas que requieren urgentemente una decisión jurisdiccional, procurando hacer realidad los principios constitucionales de efectivo acceso a la justicia y de afianzamiento de la paz social" (Zalazar, 2010:307).

En sentido coincidente, Peyrano (1999) afirma que "la medida autosatisfactiva es un requerimiento 'urgente' formulado al órgano jurisdiccional por los justiciables que se agota -de ahí lo de autosatisfactiva- con su despacho favorable, no siendo, entonces, necesaria la iniciación de una ulterior acción principal para evitar su caducidad o decaimiento, no constituye una medida cautelar por más que en la praxis muchas veces se la haya calificado, erróneamente, como una cautelar autónoma".

En nuestro país se impuso la terminología acuñada por Jorge Peyrano porque fue él quien las divulgó con ese nombre. Otros autores la denominan "Proceso urgente no cautelar" (Andorno), otros “Cautela Material” (De Lazzari, Morello), "Tutela Civil Inhibitoria” (Lorenzetti), "Tutela Anticipatoria”(Verizonce), “Tutela Inhibitoria” (Nicoleau), “Cautela Satisfactiva" (Morello).

Pero lo cierto es que la medida autosatisfactiva requiere un interés tutelable manifiesto y la necesidad de que exista una tutela inmediata imprescindible. Huelga destacar, las diferencias de estas medidas con las cautelares y la tutela anticipada, en el sentido que las autosatisfactivas no encuadran en la actividad jurisdiccional asegurativa sino en la dirimente, ya que si bien comparte con las cautelares la circunstancia de ser resueltas, en la mayoría de los casos, inaudita parte, y con las anticipatorias la de basarse en la cuasi certeza del derecho, significan lisa y llanamente el dictado de una sentencia que resuelve el conflicto a favor del demandante (Riva, 2007:32).

Sin ánimos de agotar la temática, debemos tener en cuenta que la medida autosatisfactiva puede ser revisada en una segunda instancia de lo que surge que no hace cosa juzgada y subsana el hipotético déficit o mudada la circunstancia originaria que motivó la denegatoria, el planteo podrá renovarse. Pero si por el contrario se dicta la medida y cumplida ésta autoconsume la materia litigiosa, hace cosa juzgada material, al igual que si se articula la preclusión de la vía recursiva, la decisión tiene carácter de cosa juzgada formal.

El Código Procesal Laboral de la Provincia de Córdoba (Ley 7987) no regula expresamente a estas medidas, ni tampoco lo hace el Código Procesal Civil y Comercial de aplicación supletoria. Ahora bien, aquellas leyes rituales de otras provincias que regulan las medidas autosatisfactivas, como regla general disponen que debe ser resuelta sin previa sustanciación y con ejecución inmediata, aunque suelen habilitar a que excepcionalmente de ser ponderado necesario se corra traslado simplemente para ser oído el destinatario, sin apertura a prueba².

Es dable advertir que las legislaciones del Uruguay, Brasil e Italia - por ejemplo- aceptan la tutela anticipatoria, más de ninguna manera reciben una figura semejante a las autosatisfactivas y menos aún, la contiene la Ley de Enjuiciamiento Civil Española del año 2000 (Bordenave, 2009:133). 
En síntesis, con algunas variantes y matices los procesalistas, nacionales y extranjeros, coinciden en señalar que se trata de un proceso de ejecución inmediata (auto-satisfactivo), monitorio (insustanciado), y la diferencia del generado por las medidas cautelares se caracteriza por no ser instrumental de otro principal (Andorno, 1995:887). Es una medida definitiva, autónoma y no instrumental; y para su aceptación, debe ponderarse la alta probabilidad e importancia del derecho y la irreparabilidad del perjuicio irrogado en su privación ${ }^{3}$.

Por tanto, se trata de un proceso urgente, autónomo y no accesorio, no cautelar, en el que se debe ponderar principalmente la prisa del peticionante y que se agota con la resolución que se dicta.

En este sentido, el juzgador en el caso bajo análisis sostuvo que "si bien no se encuentran aún reguladas legislativamente...poseen fundamento jurídico basados en: 1) el bloque Convencional incorporado a partir de la reforma constitucional del año 1994, principalmente el Pacto de San José de Costa Rica y Pacto Internacional de Derechos Civiles y Políticos, donde prevén la necesidad de que los estados provean una tutela judicial efectiva de los derechos de sus conciudadanos; 2) en el articulado de la Constitución Nacional: artículos catorce en cuanto establece el derecho a peticionar a las autoridades, y el diecinueve que expresamente instituye todo aquello que no está prohibido por la ley; y 3) En el artículo 3 del Código Civil y Comercial de la Nación que establece el deber de los jueces de resolver los asuntos que sean sometidos a su jurisdicción mediante una decisión razonablemente fundada. En razón de ello, es que estas medidas pueden fundamentarse en la potestad cautelar genérica o vía interpretación analógica en las disposiciones legales que prevén supuestos que pueden calificarse como acciones de esta naturaleza".

\section{Análisis y argumentos del sentenciante}

Una vez descripta -aunque sucintamente- los principales rasgos del presente proceso incumbe seguidamente analizar la procedencia de la solicitud de la parte actora. En tal sentido se destaca que la accionante solicita se declare la nulidad del despido comunicado por la empleadora encontrándose vigente la prohibición de despedir prevista por el Decreto de Necesidad y Urgencia 329/2020 y la consiguiente reinstalación laboral en su puesto de trabajo y el pago de los salarios caídos desde el distracto.

Cabe destacar que el sentenciante en primer lugar, comienza - con buen tino - realizando un "tamiz constitucional" del decreto antes mencionado para el caso concreto. Así, recurre a los estándares establecidos por nuestro máximo Tribunal Nacional (Corte Suprema de Justicia de la Nación, en adelante CSJN), en situaciones de emergencia para validar los $\mathrm{DNU}^{4}$.

Posteriormente, considera cumplimentados todos los requisitos formales, estos es, que el DNU en cuestión ha sido suscripto en Acuerdo General de Ministros, con los recaudos previstos por el art. 99 inc. $3^{\circ}$ de la Constitución Nacional ya que la materia legislada no versa sobre cuestiones excluidas por dicho precepto (penal, tributaria, electoral o régimen de partidos políticos) y se la ha comunicado a la Comisión Bilateral Permanente, en cumplimiento de la Ley 26.122.

\footnotetext{
3 Cámara Nacional de la Plata el 14/08/2012 en autos: "L., V. c. AFIP — BCRA s/ medida autosatisfactiva".

4 Causas "Peralta Luis y otros c/ Estado Nacional" (La ley 1991-C,158); "Provincia de San Luis c. Estado Nacional”, Fallos: 326:417; "Aceval Pollacchi, Julio Cesar c. Compañía de Radiocomunicaciones Móviles S.A." (CSJN, 28/06/11 - Número interno A. 996. XLI), entre otros.
} 
Con respecto a los requisitos sustanciales, también los entiende cumplidos, por cuanto las condiciones que dieron origen al DNU 329/20 y su prórroga, poseen una finalidad pública y la necesariedad de su dictado encuentra fundamento en la grave situación de riesgo social y sanitario, que afecta intereses vitales para la sociedad toda lo que habilita la delegación legislativa excepcional prevista por el art. 76 de la Constitución Nacional (en adelante, CN). En tanto, la urgencia se basa en que deviene imposible someter a una norma al trámite ordinario de sanción de las leyes, ya que el Congreso de la Nación no puede reunirse por circunstancias de fuerza mayor que lo impiden, como es la emergencia sanitaria de público conocimiento producto de la pandemia mundial (COVID 19 - Coronavirus). Asimismo, la temporalidad se encuentra cumplida al determinarse una duración primigenia de sesenta días de la medida, prorrogada por igual término, poniendo de manifiesto su transitoriedad.

Continuando con el análisis del DNU, el magistrado manifiesta que "desde el punto de vista de las condiciones socioeconómicas reales" la medida luce razonable. Es importante advertir aquí, como el juzgador utiliza, conjuga y complementa dos principios: el de razonabilidad y primacía de la realidad.

Siguiendo con los requisitos sustanciales, acerca de la proporcionalidad, la CSJN exige para validar los DNU que la norma no altere la esencia de la relación jurídica que legisla, y aquí estamos ante una normativa legal que dispone la ineficacia jurídica de los despidos sin causa (acto con objeto ilícito), resultando en caso de tomarse dicha decisión un acto anulable.

Sin embargo, el juzgador coincide con la opinión y valoración efectuada por el Dr. Diego J. Tula (2020) al considerar el DNU proporcional con el bien jurídico protegido: la fuente de trabajo. Así, haciendo suyas las palabras del precitado, manifiesta que “....la prohibición de despedir en forma incausada y por falta o disminución de trabajo y fuerza mayor, garantiza de manera adecuada la protección contra el despido arbitrario (art. 14 bis, Constitución Nacional), dentro del marco de la emergencia pública en materia económica, financiera, fiscal, administrativa, previsional, tarifaria, energética, sanitaria y social (Ley 27.541, DNU 260/2020 y DNU 297/2020), pues se verifica como necesaria para garantizar las fuentes de trabajo. Dicho de otro modo, la garantía de retribución justa contra el despido arbitrario -aún agravada por el DNU 34/2019- luce temporariamente ineficaz para garantizar el bien jurídico a proteger: preservación de la fuente de trabajo (y con ello la remuneración, la obra social, y demás beneficios de las personas que trabajan en relación de dependencia). La necesidad de proteger a las personas que trabajan de los daños inmediatos que produce habitualmente la extinción del vínculo laborativo (desempleo, ausencia de ingresos económicos, imposibilidad de acceder a un servicio de medicina privado, etc.) en un escenario excepcional de emergencia pública en materia económica, financiera, fiscal, administrativa, previsional, tarifaria, energética, sanitaria y social, debe ser seguida por una medida eficaz y contundente en esa protección. Y ello, precisamente, evidencia una de las pautas de valoración de las razones de necesidad y urgencia de la prohibición temporaria de despedir: inexistencia de otros medios alternativos adecuados para lograr los fines buscados...". Finalmente, en cuanto al control de legalidad, sostiene que la legislación de emergencia traspone el tamiz constitucional.

Una vez finiquitado el análisis constitucional, el magistrado se adentró en la plataforma fáctica de marras a los fines de resolver la cuestión brindando una resolución lógica y legal. 
Así, se debe inferir que la registración de la relación de trabajo por parte de la empleadora resultó tempestiva y en consecuencia dicha relación se encontraba cursando el periodo de prueba. Este último se trata del lapso caracterizado como el primer tramo del contrato de trabajo por tiempo indeterminado, donde cualquiera de las partes posee la facultad de extinguir el vínculo sin expresión de causa y sin obligación de abonar una indemnización. Es decir, que las personas que se encuentren atravesando los primeros tres meses de la relación laboral, no gozan aun de estabilidad impropia -protección contra el despido arbitrario- consagrada en el art. 14 bis de la Constitución Nacional (art. 92 bis, L.C.T.).

En palabras de Etala (1998), el período de prueba es un período de carencia, cuyo transcurso es necesario para que puedan encontrar aplicación en plenitud las normas de protección que corresponden a un contrato de trabajo por tiempo indeterminado. Por su parte, Montoya Melgar (2000) nos ilustra que el contrato de trabajo a prueba es el negocio jurídico bilateral mediante el cual el empresario y el trabajador pretenden el conocimiento empírico de las condiciones contractuales que habrán de regir en el futuro, buscando por consiguiente experimentar sobre el terreno de la relación de trabajo mediante la ejecución de las prestaciones respectivas de las partes.

En este momento del comentario, es dable destacar la comparación normativa que se efectúa en el fallo y sobre la cual, se pronunciará a posteriori el magistrado. Precisamente, se analiza cómo se compatibilizan las disposiciones de la LCT vinculadas al periodo de prueba con los DNU 329 y 487/2020, que disponen la prohibición de despedir. En este orden, el magistrado citando al Dr. Sergio Omar Rodríguez (2020) destaca que doctrinariamente existen posturas encontradas sobre la solución que debería adoptarse. Por una parte, la postura que afirma que prevalece el artículo 92 bis, por sobre el decreto 329/20, que tiene fundamentos en una lectura más inclusiva de ambas partes en el contrato de trabajo. Esto quiere decir, que si bien entiende que adolece un contexto excepcional, interpreta que los efectos lesivos de la pandemia afectan de un lado y del otro de la relación laboral. En tal sentido, se argumenta que bastante daño implicará el esfuerzo de mantenerse abonando salarios el empleador en medio de la caída de su rentabilidad, incluso yendo a pérdida negocial, como para eso sumarle la obligación de mantener un vínculo el cual en tiempos normales no hubiese tenido que sustentar si hubiera despedido en modo previo. El despido en los términos del artículo 92 bis es cierto que implica un daño para ese trabajador, pero muy inferior atento al grado de perspectiva que se puede tener cuando un trabajador sabe que está a prueba. Esta postura, aplica un orden de prelación directo, en tanto entiende a la ley general, la LCT, como superior frente a un decreto contingencial y de carácter temporal.

Por otro lado, existe doctrinariamente una corriente que sostiene que el decreto 329/2020 que dispone la prohibición de los despidos en la República Argentina por el término de 60 días, es aplicable a los trabajadores en período de prueba. Autores doctrinales destacadísimos como el Dr. Sergio Adrián Arce, sostienen que sin lugar a dudas el análisis de la coyuntura de las relaciones laborales en época de pandemia debe llevarse a cabo bajo el tamiz de los principios protectorios del derecho del trabajo. Esto hace, que el carácter tuitivo de la relación de trabajo, extienda los efectos del DNU 329/20, ya que sostiene el doctrinario, que no hay que hacer distinción de trabajadores que ni el propio decreto realiza. 
En sentido coincidente, el juez del caso de marras entiende que no se puede adoptar de manera absoluta y general una u otra posición, pero en el caso concreto consagra que resulta aplicable el DNU $N^{\circ} 329 / 20$ y su prorroga $N^{\circ} 487 / 20$. Para ello, el sentenciante aduce que la notificación del despido incausado ingresó a la esfera de conocimiento de la trabajadora - teoría de la recepción (Lascano y Calvimonte, 2019: 145) - encontrándose vigente la prohibición de despedir ${ }^{5}$.

En segundo término, analiza y tiene presente las condiciones personales de la actora, en tanto resulta sostén de hogar, que además es madre de una menor de edad y se encuentra cursando un embarazo, lo que la ubica en una situación de vulnerabilidad en los términos del Art. 9 de la convención de Belem do Pará (ratificada por Ley 24.632). Ello sumado al escenario de emergencia nos obliga a aplicar principios convencionales vigentes, que poseen estatus constitucional a partir de la reforma del año 1994, como son los compromisos asumidos por nuestro país mediante la suscripción de la Convención sobre la eliminación de todas las formas de discriminación contra la mujer (en adelante CEDAW). Sobre este fundamento, acerca de la especial tutela que merece y se le dispensa a la maternidad, nos detendremos en el acápite subsiguiente.

Continuando con su tarea argumental y abonando su postura en el sentido de otorgarle primacía al DNU por sobre la LCT en el caso concreto, el Tribunal menciona expresamente las Reglas de Brasilia. Entre estas Reglas, que definen las causas de vulnerabilidad, se mencionan, el género (regla 4) y la pobreza (regla 15), entendiendo que la discriminación que la mujer sufre en determinados ámbitos supone un obstáculo para el acceso a la justicia, que se ve agravado en aquellos casos en los que concurra alguna otra causa de vulnerabilidad (regla 17) y busca promover las condiciones necesarias para que la tutela judicial de los derechos reconocidos por el ordenamiento sea efectiva, adoptando aquellas medidas que mejor se adapten a cada condición de vulnerabilidad (regla 25), debiendo preservar en toda intervención en un acto judicial la dignidad de la persona en condición de vulnerabilidad, otorgándole un trato específico adecuado a las circunstancias propias de su situación (regla 50).

De este modo, las decisiones judiciales se deben configurar, como un instrumento para la defensa efectiva de los derechos de las personas en condición de vulnerabilidad, ya que de nada sirve que el Estado reconozca formalmente un derecho si su titular no puede acceder a la tutela efectiva del mismo, y así asegurar el eficaz cumplimiento de la transversalización que supone el derecho de acceso a la justicia, entendido como "el derecho a la igualdad ante los tribunales y cortes de justicia y a un juicio imparcial, y como elemento fundamental de la protección de los derechos humanos" (Sbdar, 2017: 1).

Por estos fundamentos y en virtud de la excepcionalidad de la situación y jerarquía del bien jurídico tutelado constitucionalmente, sumado a la imposibilidad en el contexto actual de obtener un nuevo empleo, cobertura de obra social, máxime si se tiene en cuenta su estado de embarazo, sostén de su grupo familiar, todo lo cual provocaría un daño inmediato a la pérdida del derecho causado por el riesgo de la demora en la tramitación de un proceso ordinario, el juzgador resuelve que existen elementos probatorios suficientes que demuestran que el despido acaecido debe enmarcarse dentro de la prohibición establecida por el DNU n³29/20 y por consiguiente, dispone la procedencia de la medida

\footnotetext{
5 Nuestro más alto Tribunal provincial, adopta en sus pronunciamientos la teoría de la recepción, por ejemplo en autos: Ocampo Marcelo Gustavo c/ GTL S.A. y otros - Ordinario Despido - Recurso de Casación Sent. 136/14; Pasetti, Franco Ramón c/ Tigero Ricardo (Betel Ejecutivo) - Ordinario Despido - Recurso de Casación, Sent. $\mathrm{N}^{\circ} 159 / 17$, entre otros.
} 
autosatisfactiva impetrada por la actora, declarando la nulidad del despido y ordenando la reincorporación de la trabajadora.

Por último, en su resuelvo y en cumplimiento de las Reglas de Brasilia ${ }^{6} N^{\circ} 58$ a 60, el magistrado le dedica una parágrafo a la actora. Estas Reglas, recordemos tienen como objetivo garantizar las condiciones de acceso efectivo a la justicia de las personas en condición de vulnerabilidad, sin discriminación alguna, englobando el conjunto de políticas, medidas, facilidades y apoyos que permitan a dichas personas el pleno goce de los servicios del sistema judicial.

En este sentido, el funcionario judicial le comunica a la actora, “...finalmente decidí hacer lugar a tu reclamo, teniendo presente que, si bien el despido se produjo cuando el periodo de prueba no estaba cumplido, justo te lo comunicaron cuando entró en vigencia el decreto presidencial que prohibía los despidos. Además el hecho de encontrarte embarazada y ser sostén de hogar me obliga a tener muy en cuenta esa situación, para que mi resolución cumpla con las pautas que me dan las leyes locales y los convenios internacionales en materia de derechos humanos, para las personas en situación de vulnerabilidad...", y continua expresándole a la trabajadora, "te pido que aproveches la oportunidad y asumas lo resuelto con toda responsabilidad, teniendo en cuenta el gran esfuerzo que le ordena cumplir a tu empleadora".

\section{Marco Normativo Aplicable. Bloque de Constitucionalidad}

Por todo lo hasta aquí expresado, entendemos que la protección de la mujer en contra de cualquier tipo de discriminación laboral, sea en el ámbito público como el privado, debe ser una principal preocupación de los magistrados del trabajo.

En este orden de ideas, merece un acápite la aplicación expresa formulada por el juzgador de los convenios internacionales en materia de derechos humanos con jerarquía constitucional y supralegal, como lo son la Convención de Belem do Pará y Convención sobre la eliminación de todas las formas de discriminación contra la mujer (CEDAW).

La Convención Interamericana para Prevenir, Sancionar y Erradicar la violencia contra la mujer, "Convención de Belem Do Pará", ratificada por nuestro país por Ley 24.632, consagra en su artículo 9 que “...los Estados Partes tendrán especialmente en cuenta la situación de vulnerabilidad a la violencia que pueda sufrir la mujer en razón, entre otras, de su raza o de su condición étnica, de emigrante, refugiada o desplazada. En igual sentido se considerará a la mujer que es objeto de violencia cuando está embarazada, es discapacitada, menor de edad, anciana, o está en situación socioeconómica desfavorable o afectada por situaciones de conflictos armados o de privación de su libertad"7 .

A su turno, la Convención sobre la Eliminación de todas las Formas de Discriminación contra la Mujer, conocida por sus siglas en inglés como CEDAW (Convention on the Elimination of All Forms of Discrimination against Women), fue adoptada en diciembre de 1979 por Resolución 34/180 de la Asamblea General de las Naciones Unidas. La Argentina la aprobó mediante ley 23.179 de junio de 1985 y desde 1994 goza de jerarquía constitucional (art. 75, inc. 22, CN). La CEDAW toma como punto de partida la discriminación estruc-

\footnotetext{
6 Aprobadas en la XIV Cumbre Judicial Iberoamericana realizada en Brasilia en marzo de 2008.

7 Debemos recordar que dicha Convención en su Artículo 8 inc. c), reza: "Fomentar la educación y capacitación del personal en la administración de justicia, policial y demás funcionarios encargados de la aplicación de la ley, así como del personal a cuyo cargo esté la aplicación de las políticas de prevención, sanción y eliminación de la violencia contra la mujer".
} 
tural e histórica hacia las mujeres, reconociendo y protegiendo sus derechos. A su vez, en el año 2006, mediante ley 26.171, la Argentina aprobó el Protocolo Facultativo de la CEDAW, adoptado por la Asamblea General de las Naciones Unidas en octubre de 1999.

En idéntico sentido, nuestro más alto Tribunal Nacional recomienda extrema prudencia para estos casos de específica tutela que dispensa el ordenamiento jurídico a la maternidad (Fallos: 318:871) como sujeto de especial tutela constitucional, así como la normativa de jerarquía constitucional que enmarca la tutela de la mujer embarazada en las relaciones laborales, entre ellas el art. 75 inc. 23 en cuanto establece que corresponde al Congreso de la Nación: “Legislar y promover medidas de acción positiva que garanticen la igualdad real de oportunidades y de trato, y el pleno goce y ejercicio de los derechos reconocidos por esta Constitución y por los tratados internacionales vigentes sobre derechos humanos, en particular respecto de los niños, las mujeres, los ancianos y las personas con discapacidad. Dictar un régimen de seguridad social especial e integral en protección del niño en situación de desamparo, desde el embarazo hasta la finalización del período de enseñanza elemental y de la madre durante el embarazo y el tiempo de lactancia".

Así, la CEDAW conforme los términos del art. 4 y en particular el art. 11, establece que “...con el fin de impedir la discriminación contra la mujer por razones de matrimonio o maternidad y asegurar la efectividad de su derecho a trabajar, los Estados partes tomarán medidas adecuadas para: a) prohibir, bajo pena de sanciones, el despido por motivo de embarazo o licencia de maternidad y la discriminación en los despidos sobre la base del estado civil...".

Asimismo, es menester tener en cuenta que el Estado provincial dictó la Ley Provincial Nro. 10401, que "establece aspectos jurisdiccionales y procesales vinculados a la aplicación, en el ámbito de la Provincia de Córdoba, de las disposiciones pertinentes de la Ley Nacional $N^{\circ} 26485$, cuya adhesión se dispuso mediante Ley $N^{\circ} 10352$, tendiente a fortalecer el marco procesal vigente para asegurar a las víctimas de violencia hacia las mujeres por cuestiones de género, una protección integral en instancias administrativas y jurisdiccionales, contribuyendo a hacer reales y efectivos los principios de equidad consagrados en la Constitución Nacional, protegiendo su integridad física, psíquica, sexual, libertad y trato igualitario, seguridad y no discriminación por su condición de mujer"8.

Finalmente, también en las Reglas de Brasilia se consagra que la discriminación que la mujer sufre en determinados ámbitos supone un obstáculo para el acceso a la justicia, que se ve agravado en aquellos casos en los que concurra alguna otra causa de vulnerabilidad. La mentada normativa entiende por discriminación contra la mujer, toda distinción, exclusión o restricción basada en el sexo que tenga por objeto o resultado menoscabar o anular el reconocimiento, goce o ejercicio por la mujer, independientemente de su estado civil, sobre la base de la igualdad del hombre y la mujer, de los derechos humanos y las libertades fundamentales en las esferas política, económica, social, cultural y civil o en cualquier otra esfera (Regla 18) y considera violencia contra la mujer, cualquier acción o conducta, basada en su género, que cause muerte, daño o sufrimiento físico, sexual o psicológico a la mujer, tanto en el ámbito público como en el privado, mediante el empleo de la violencia física o psíquica (Regla 19). 
En su consecuencia, se impulsarán las medidas necesarias para eliminar la discriminación contra la mujer en el acceso al sistema de justicia para la tutela de sus derechos e intereses legítimos, logrando la igualdad efectiva de condiciones, prestando una especial atención en los supuestos de violencia contra la mujer, estableciendo mecanismos eficaces destinados a la protección de sus bienes jurídicos, al acceso a los procesos judiciales y a su tramitación ágil y oportuna (Regla 20).

Por lo expuesto, coincidimos in totum con el juzgador del caso de marras, en que los magistrados en aquellos procesos donde se encuentra amenazado o vulnerado el derecho a la igualdad y no discriminación de las mujeres, tienen la obligación de fallar con perspectiva de género ${ }^{9}$.

\section{Reflexión Final}

Como colofón, podemos destacar varios aspectos del fallo que nos ocupa. En un primer término, la primacía normativa que le otorgó el magistrado al DNU por sobre el articulado de la Ley de Contrato de Trabajo referido al período de prueba, siendo conteste con la doctrina que entiende que "...el Decreto 329/2020 no sólo va en línea con las facultades que se le reconocen constitucionalmente al Presidente de la República, sino que además se encuentra hermanado con la lógica y el sentido tutelar con que el derecho social pretende la especial relación que se materializa entre un trabajador y el empleador -actuando como consecuencia de ello- en beneficio del sujeto hiposuficiente dentro del vínculo laboral" (Balbín, 2020: 2), más aun tratándose de una trabajadora embarazada, sostén de hogar y con un menor a su cargo.

Tal como señala Orsini (2020) "no existe objeción constitucional alguna para ordenar judicialmente la nulidad del despido y la reinstalación en favor de los trabajadores del sector privado. Máxime cuando el art. 7.d. del Protocolo de San Salvador (instrumento con jerarquía supra legal en el país) consagra expresamente el derecho a la estabilidad y la readmisión del trabajador despedido como uno de los mecanismos de garantizar el derecho al trabajo". En este marco, creemos necesario que en esta actualidad de grave riesgo para la salud pública, las condiciones del mercado deben ser orientadas al servicio del Ser Humano y no a la inversa.

En segundo lugar, poner de resalto la aplicación expresa y concreta que formula el juzgador del llamado bloque de constitucionalidad y con ello, tratados internacionales con jerarquía constitucional y supra legal como lo son, la Convención sobre la Eliminación de todas las Formas de Discriminación contra la Mujer (CEDAW) y la Convención Interamericana para Prevenir, Sancionar y Erradicar la violencia contra la mujer (Convención de Belem Do Pará) ya que consideramos que la protección de la mujer en contra de cualquier tipo de discriminación laboral debe ser una principal preocupación de los magistrados del trabajo y en aquellos casos donde se encuentra amenazado o vulnerado el derecho a la igualdad y no discriminación de las mujeres, los tribunales tienen la obligación de fallar con perspectiva de género atento que esta última es una cuestión transversal a todas las ramas jurídicas.

Finalmente, es menester tener en cuenta el parágrafo que se le dedica a la trabajadora en virtud de las Reglas de Brasilia porque debemos ser conscientes de quienes son los

9 Fallo “R. L. S. vs Sanatorio 9 de Julio S.A. S/ Cobro de pesos", Juzg. del Trabajo III Nominación, San Miguel de Tucumán, citado por el Dr. Juan Facundo Quiroga Contreras. 
destinatarios reales de las resoluciones judiciales en el ámbito laboral. De este modo, concluimos que producto de los tiempos que corren, nunca resultó más claro que el Estado así como el régimen jurídico en su totalidad, deben procurar como su fin último, la protección de la persona humana con especial consideración de la persona que trabaja bajo una relación de dependencia (art. 14 bis, CN -Principio Protectorio), más aun cuando se trata de una persona en condiciones de vulnerabilidad.

\section{REFERENCIAS BIBLIOGRÁFICAS}

- Andorrno, L.O. (1995). El denominado proceso urgente no cautelar en el derecho argentino como instituto similar a la acción inhibitoria del Derecho italiano. J.A. T. II-887.

- Balbín, A. (2020). Acerca de la constitucionalidad del decreto de necesidad y urgencia que prohíbe los despidos y las suspensiones en el marco de la crisis del COVID-19, Derecho del Trabajo y Coronavirus. Revista La Ley, Tomo B.

- Bordenave, L. (2009). La medida autosatisfactiva como solución inconstitucional para un problema de la justicia moderna. Rosario: Juris.

- Etala, C.A. (1998). Contrato de trabajo. Buenos Aires: Astrea.

- Lascano, E.J. y Calvimonte, B. (2019). Derecho del Trabajo - Interpretación Judicial Jurisprudencia Sala Laboral T.S.J. 2005-2018. Córdoba: Advocatus.

- Marcellino, V. (2013). Procesos Urgentes: Despacho interino de fondo y medida autosatisfactiva. Revista Catorce bis año XV, $n^{\circ} 45$.

- Montoya Melgar, A. (2000). El período de prueba en el contrato de trabajo. Madrid: Tecnos.

- Orsini, J.I. (2020). Estabilidad absoluta temporal y nulidad de los despidos en el Decreto N. ${ }^{\circ 329 / 2020 ~ e n ~ C O V i D-19 ~ y ~ s u ~ i m p a c t o ~ e n ~ l a s ~ r e l a c i o n e s ~ l a b o r a l e s ~ e n ~ A r g e n t i n a: ~ r e f l e x i o-~}$ nes iniciales en estos tiempos. Disponible en: https://ar.ijeditores.com/pop.php?option= articulo\&Hash=cfb461 dcf66587ee43015d8d4f0a5a7f.

- Peyrano, J.W. (1999). Régimen de las medidas autosatisfactivas. Nuevas propuestas, en Medidas autosatisfactivas. Buenos Aires: Rubinzal Culzoni.

- Riva, A. A. (2007). Medidas cautelares. Buenos Aires: Lexis Nexis.

- Rodríguez, S.O. (2020). Las dos posiciones frente a los despidos en el período de prueba (Art. 92 bis, LCT), en plena vigencia del Decreto 329/2020 que prohíbe los despidos. Disponible en: http://www.saij.gob.ar/DACF200090.

- Sbdar, C. (2017). La transversalización de la perspectiva de género: un enfoque necesario. Revista La Ley, año LXXXI No 112.

- Zalazar, C. E. (2010). Medidas Cautelares. Cordoba: Alveroni. 